\title{
STRES SEDANG DAN STRATEGI KOPING ADAPTIF YANG DIALAMI PELAKU RAWAT INFORMAL DALAM PERAWATAN PALIATIF
}

\author{
Barnis Lady Mentari Alamdani ${ }^{1 *}$, Tuti Nuraini ${ }^{2}$ \\ 1. Program Studi Sarjana, Fakultas Ilmu Keperawatan, Universitas Indonesia, Depok 16424, Indonesia \\ 2. Fakultas Ilmu Keperawatan, Universitas Indonesia, Depok 16424, Indonesia \\ *Email: barnis.lady@gmail.com
}

\begin{abstract}
Abstrak
Pelaku rawat informal berisiko untuk mengalami stres berlebih dan koping maladaptif dalam merawat klien diabetes pada perawatan paliatif. Penelitian ini bertujuan untuk mengetahui tingkat stres dan strategi koping pelaku rawat informal dalam perawatan paliatif. Desain penelitian menggunakan cross sectional dengan melibatkan sebanyak adalah 40 pelaku rawat sebagai responden. Instrumen yang digunakan yaitu kuesioner PSS 14 items dan CSI-SF 32 items. Hasil penelitian menunjukkan bahwa mayoritas pelaku rawat mengalami stres sedang (95\%) dan koping yang sering digunakan adalah koping adaptif. Tidak ada hubungan antara tingkat stres dan karakeristik pelaku rawat informal (95\% $\mathrm{CI}$; p >0.05). Penelitian ini merekomendasikan penyedia jasa pelayanan paliatif untuk mengevaluasi pelayanan yang ada sehingga mengurangi stres dari para pelaku rawat informal dalam perawatan paliatif.
\end{abstract}

Kata kunci: diabetes melitus, pelaku rawat informal, perawatan paliatif, strategi koping, stress

\section{Abstract}

Medium Stress and its Adaptive Coping Strategy of the Informal Caregivers in Palliative Care. Informal caregivers have risks to experience excessive stress and maladaptive coping when caring patient with diabetes in palliative care. This study was conducted to describe stress and coping strategies of informal caregivers in palliative care with cross sectional design. The sample was 40 caregivers. The instrument of this study was a questionnaire PSS14item sand CSISF 32 items. The results showed that most of caregivers had been through moderate stress (95\%) and often used adaptive coping. These result also showed that no significant relationship between level of stress and characteristic of informal caregivers (95\% CI; $p$ >0.05). Based on these results, the institutions that provide palliative care should evaluate their services to reduce stress level of informal caregivers.

Keywords: coping strategies, diabetes melitus, informal caregivers, palliative care, stress

\section{Pendahuluan}

Diabetes mellitus merupakan salah satu penyakit kronis yang termasuk ke dalam golongan Penyakit Tidak Menular (PTM). PTM menjadi penyakit yang menyebabkan kematian di Indonesia dengan proporsi dari 49.9\% pada tahun 2001 menjadi $59.5 \%$ pada tahun 2007 (Kemkes RI, 2012). World Health Organization (WHO) juga memperkirakan peningkatan kematian yang disebabkan PTM akan terus meningkat di negara-negara menengah dan miskin.
Pelaku rawat merupakan seseorang yang mengurus keseharian klien dan mendedikasikan waktu mereka untuk aktivitas yang sebanding dengan standar pekerja pada umumnya (Ferrara, et al., 2008). Pelaku rawat informal dapat berasal dari sukarelawan, atau saudara dekat dari klien dan keluarganya. Pemberian perawatan paliatif yang secara komprehensif terkadang membuat para pelaku rawat ini mengalami stres.

Penelitian sebelumnya menunjukkan bahwa setengah dari 83 pelaku rawat informal sering 

merasa kewalahan dan merasa kesal atau mengalami ketegangan emosional (Sinclair, Armes, Randhawa, \& Bajer, 2010). Ketika seseorang mendapatkan stresor, maka respons yang dilakukan disebut sebagai strategi koping, respons koping, atau mekanisme koping. Koping adalah upaya kognitif dan perilaku untuk mengatur tuntutan/stresor internal dan eksternal yang dinilai sebagai beban yang melebihi kemampuan pada setiap orang (Berman, Snyder, Kozier, \& Erb, 2008).

Lee (2008) dalam penelitiannya juga menemukan bahwa $9.7 \%$ dari 1.000 pelaku rawat informal di Korea pernah memukul kliennya dan $2.5 \%$ pelaku rawat keluarga seringkali meninggalkan klien tanpa pengawasan. Kondisi distres pada saat aktiftas sehari-hari dan perasaan kelelahan dalam bekerja ini mengakibatkan kurang efektifnya perawatan. Penelitian eksperimen yang telah dilakukan untuk menanggulangi kondisi stres ini adalah berupa intervensi dukungan terhadap manajemen diri klien diabetes dengan menggunakan pelayanan Health Interactive Voice Responsse (IVR) yang membutuhkan bantuan dari pelaku rawat informal kliennya (Aikens, Zivin, Trivedi, \& Piette, 2014).

Masyarakat di Indonesia belakangan ini sudah banyak menyadari pentingnya pemeliharaan kesehatan, sehingga kebutuhan terhadap pelaku rawat informal juga meningkat. Pelaku rawat informal ini biasanya sudah mendapatkan pelatihan tentang aspek perawatan terkait klien yang dirawatnya. Penelitian tentang klien dan penyakit diabetes sudah banyak dilakukan tetapi terkait pelaku rawat informal ini masih harus lebih banyak dikembangkan. Mengingat dampak stres pelaku rawat informal pada kondisi klien yang dirawatnya maka penting dikaji tingkat stres dan koping yang dialami pelaku rawat informal, khususnya di Indonesia.

\section{Metode}

Penelitian ini berlangsung selama tiga minggu di berbagai Balai Asuhan Keperawatan luka diabetes wilayah Jabodetabek. Responden penelitian ini adalah pelaku rawat informal dari pihak klien yang terdaftar di Balai Asuhan Keperawatan.

Penelitian cross sectional ini menggunakan teknik pengambilan sampel consecutive untuk mendapatkan 40 pelaku rawat informal sebagai responden. Kriteria inklusi responden yaitu berusia antara 20 tahun sampai lebih 65 tahun, dan sedang/pernah berperan dalam perawatan paliatif dalam waktu lebih dari satu bulan.

Kuesioner yang digunakan adalah terjemahan dari Perceived Stress Scale dengan 14 item pernyataan oleh Cohen, Kamarck dan Mermelstein (1983) dan Coping Strategies Inventory Short Form dengan 32 item pernyataan oleh Tobin (2011). Setiap kuesioner memiliki lima opsi jawaban dengan intensitas tidak pernah, sesekali, terkadang, sering, dan selalu. Nilai skor adalah jumlah dari keseluruhan nilai kemudian dikategorikan. Kategori tersebut untuk tingkat stres yaitu stres rendah (0-14), stres sedang (15-28), stres tinggi (29-42) dan stres sangat tinggi (43-56). Sedangkan untuk kategori koping yaitu koping adaptif (115-160) dan koping maladaptif (32-114).

\section{Hasil}

Tabel 1 menunjukkan bahwa responden paling banyak pada tahap usia dewasa awal (20-40 tahun), yaitu 21 responden $(52.5 \%)$. Mayoritas perempuan yaitu 28 responden (70\%). Responden juga sebagian besar berpendidikan SMA yaitu sebanyak 15 responden (37.5\%). Mayoritas sudah menikah yaitu sebanyak 33 responden $(82.5 \%)$. Sebanyak 27 responden $(67.5 \%)$ merawat selama sekitar tiga bulan.

Tabel 2 menunjukkan bahwa mayoritas responden mengalami stres sedang yaitu sebanyak 38 responden (95\%). Jumlah responden yang menggunakan koping adaptif sebanyak 21 responden $(52.5 \%)$. 
Tabel 3 menunjukkan bahwa responden paling banyak berada pada tahap usia dewasa awal. Responden pada tahap usia tersebut mengalami tingkat stres sedang yaitu sebanyak 19 responden (90.5\%). Mayoritas responden perempuan memiliki tingkat stres sedang, yaitu sebanyak 26 responden (92.6\%). Sebanyak 14 responden $(93.3 \%)$ yang memiliki tingkat pendidikan SMA mengalami tingkat stres sedang. Mayoritas responden yang sudah menikah juga mengalami tingkat stres sedang yaitu sebanyak 32 responden (97\%). Sebanyak 25 responden $(92.6 \%)$ dengan lama perawatan kurang dari atau selama 3 bulan mengalami tingkat stres sedang dan 2 responden lainnya (7.4\%) mengalami tingkat stres tinggi. Hasil uji statistik yang dilakukan mendapatkan hasil bahwa tidak ada hubungan antara karateristik responden dengan tingkat stres yang dialami $\left(\mathrm{H}_{0}\right.$ gagal ditolak).

Tabel 1. Karakteristik Responden

\begin{tabular}{lcc}
\hline \multicolumn{1}{c}{ Variabel } & Jumlah & $(\%)$ \\
\hline Usia & 21 & 52.5 \\
Dewasa Awal & 15 & 37.5 \\
Dewasa Tengah & 4 & 10 \\
Dewasa Akhir & & \\
Jenis Kelamin & 12 & 30 \\
Laki-Laki & 28 & 70 \\
Perempuan & & \\
Tingkat Pendidikan & 7 & 17.5 \\
SD & 4 & 10 \\
SMP & 15 & 37.5 \\
SMA & 14 & 35 \\
PT & & \\
Status Pernikahan & & \\
Belum Menikah & 7 & 17.5 \\
Menikah & 33 & 82.5 \\
Lama Perawatan & & \\
$\leq 3$ bulan & 27 & \\
> 3 bulan & 13 & \\
\hline
\end{tabular}

Tabel 2. Tingkat Stres dan Koping

\begin{tabular}{lcc}
\hline \multicolumn{1}{c}{ Variabel } & Jumlah & $(\boldsymbol{\%})$ \\
\hline Tingkat Stres & & \\
Ringan & 0 & 0 \\
Sedang & 38 & 95 \\
Tinggi & 2 & 5 \\
Sangat Tinggi & 0 & 0 \\
Strategi Koping & & \\
Adaptif & 21 & 52.5 \\
Maladaptif & 19 & 47.5 \\
\hline
\end{tabular}

Tabel 3. Tingkat Stres berdasarkan Karakteristik Responden

\begin{tabular}{|c|c|c|c|}
\hline \multirow{2}{*}{ Kategori } & \multicolumn{2}{|c|}{ Tingkat Stres } & \multirow{2}{*}{ P value } \\
\hline & Sedang & Tinggi & \\
\hline \multicolumn{4}{|l|}{ Usia } \\
\hline Dewasa Awal & $\begin{array}{c}19 \\
90.5 \%\end{array}$ & $\begin{array}{c}2 \\
21 \%\end{array}$ & \multirow{3}{*}{0.729} \\
\hline Dewasa Tengah & $\begin{array}{c}15 \\
100 \%\end{array}$ & 0 & \\
\hline Dewasa Akhir & $\begin{array}{c}4 \\
100 \%\end{array}$ & 0 & \\
\hline \multicolumn{4}{|l|}{ JenisKelamin } \\
\hline Laki - Laki & $\begin{array}{c}12 \\
100 \%\end{array}$ & 0 & \multirow{2}{*}{1.000} \\
\hline Perempuan & $\begin{array}{c}26 \\
92.6 \%\end{array}$ & $\begin{array}{c}2 \\
7.1 \%\end{array}$ & \\
\hline \multicolumn{4}{|c|}{ Tingkat Pendidikan } \\
\hline $\mathrm{SD}$ & $\begin{array}{c}7 \\
100 \%\end{array}$ & 0 & \multirow{4}{*}{0.997} \\
\hline SMP & $\begin{array}{c}4 \\
100 \%\end{array}$ & 0 & \\
\hline SMA & $\begin{array}{c}14 \\
93.3 \%\end{array}$ & $\begin{array}{c}1 \\
6.7 \%\end{array}$ & \\
\hline PT & $\begin{array}{c}13 \\
92.9 \%\end{array}$ & $\begin{array}{c}1 \\
7.1 \%\end{array}$ & \\
\hline \multicolumn{4}{|c|}{ Status Pernikahan } \\
\hline Belum Menikah & $\begin{array}{c}6 \\
85.7 \%\end{array}$ & $\begin{array}{c}1 \\
14.3 \%\end{array}$ & \multirow{2}{*}{0.323} \\
\hline Sudah Menikah & $\begin{array}{c}32 \\
97 \%\end{array}$ & $\begin{array}{c}1 \\
3 \%\end{array}$ & \\
\hline \multicolumn{4}{|l|}{ Lama Perawatan } \\
\hline$\leq 3$ bulan & $\begin{array}{c}25 \\
92.6 \%\end{array}$ & $\begin{array}{c}2 \\
7.4 \%\end{array}$ & \multirow{2}{*}{1.000} \\
\hline$>3$ bulan & $\begin{array}{c}13 \\
100 \% \\
\end{array}$ & $\begin{array}{l}0 \\
0 \\
\end{array}$ & \\
\hline
\end{tabular}


Tabel 4. Koping berdasarkan Karakteritik Responden

\begin{tabular}{|c|c|c|c|}
\hline \multirow{2}{*}{ Kategori } & \multicolumn{2}{|c|}{ Koping } & \multirow{2}{*}{$\begin{array}{c}\mathbf{P} \\
\text { value }\end{array}$} \\
\hline & Adaptif & Maladaptif & \\
\hline \multicolumn{4}{|l|}{ Usia } \\
\hline Dewasa Awal & $\begin{array}{c}9 \\
42.9 \%\end{array}$ & $\begin{array}{c}12 \\
57.1 \%\end{array}$ & \multirow{3}{*}{0.806} \\
\hline Dewasa Tengah & $\begin{array}{c}10 \\
66.7 \%\end{array}$ & $\begin{array}{c}5 \\
33.3 \%\end{array}$ & \\
\hline Dewasa Akhir & $\begin{array}{c}2 \\
50 \%\end{array}$ & $\begin{array}{c}2 \\
50 \%\end{array}$ & \\
\hline \multicolumn{4}{|l|}{ Jenis Kelamin } \\
\hline Laki - Laki & $\begin{array}{c}8 \\
66.7 \%\end{array}$ & $\begin{array}{c}4 \\
33.3 \%\end{array}$ & \multirow{2}{*}{0.407} \\
\hline Perempuan & $\begin{array}{c}13 \\
46.4 \%\end{array}$ & $\begin{array}{c}15 \\
53.6 \%\end{array}$ & \\
\hline \multicolumn{4}{|l|}{$\begin{array}{l}\text { Tingkat } \\
\text { Pendidikan }\end{array}$} \\
\hline SD & $\begin{array}{c}2 \\
28.6 \%\end{array}$ & $\begin{array}{c}5 \\
71.4 \%\end{array}$ & \multirow{4}{*}{0.910} \\
\hline SMP & $\begin{array}{c}2 \\
50 \%\end{array}$ & $\begin{array}{c}2 \\
50 \%\end{array}$ & \\
\hline SMA & $\begin{array}{c}10 \\
66.7 \%\end{array}$ & $\begin{array}{c}5 \\
33.3 \%\end{array}$ & \\
\hline PT & $\begin{array}{c}7 \\
50 \%\end{array}$ & $\begin{array}{c}7 \\
50 \%\end{array}$ & \\
\hline \multicolumn{4}{|l|}{$\begin{array}{l}\text { Status } \\
\text { Pernikahan }\end{array}$} \\
\hline Belum Menikah & $\begin{array}{c}2 \\
28.6 \%\end{array}$ & $\begin{array}{c}5 \\
71.4 \%\end{array}$ & \multirow{2}{*}{0.226} \\
\hline Sudah Menikah & $\begin{array}{c}19 \\
57.6 \%\end{array}$ & $\begin{array}{c}14 \\
42.4 \%\end{array}$ & \\
\hline \multicolumn{4}{|l|}{$\begin{array}{l}\text { Lama } \\
\text { Perawatan }\end{array}$} \\
\hline$\leq 3$ bulan & $\begin{array}{c}16 \\
59.3 \%\end{array}$ & $\begin{array}{c}11 \\
40.7 \%\end{array}$ & \\
\hline$>3$ bulan & $\begin{array}{c}5 \\
38.5 \% \\
\end{array}$ & $\begin{array}{c}8 \\
61.5 \% \\
\end{array}$ & 0.370 \\
\hline
\end{tabular}

\section{Pembahasan}

Karakteristik pelaku rawat informal di wilayah Jabodetabek paling banyak berada pada tahap usia dewasa awal dan dewasa tengah, mayoritas sudah menikah, dan telah menempuh pendidikan SMA, serta masih atau telah melakukan perawatan kurang atau sekitar tiga bulan. Hasil penelitian ini tidak jauh berbeda dengan hasil penelitian sebelumnya yang dilakukan di Indonesia yang juga menunjukkan bahwa karakteristik usia pelaku rawat informal berada pada tahap dewasa awal dan dewasa tengah (Rafiyah, Suttharangsee, \& Sangchan, 2011; Riasmini, Kanso, Sahar, \& Prasetyo, 2013).

Hasil penelitian ini menunjukkan bahwa mayoritas responden mengalami tingkat stres sedang yaitu sebanyak 95\%. Hasil penelitian ini berbeda dengan penelitian sebelumnya di Amerika Serikat yang menemukan bahwa pelaku rawat memiliki stres tinggi yang tetap dan kumulatif dari waktu ke waktu. Kondisi ini berdampak kurang baik pada perencanaan perawatan klien (Spillman \& Long, 2009). Perbedaan tingkat stress ini dapat terjadi karena budaya dan status hubungan pelaku rawat dengan kliennya. Masyarakat di Indonesia dikenal memiliki hubungan kekeluargaan yang kuat (Effendy et al., 2015). Hal ini akan bermakna pada dukungan sosial. Budaya ini membuat pelaku rawat terpenuhi dalam aspek dukungan sosialnya. Hasil penelitian oleh Effendy et al., (2014) ini juga menjelaskan bahwa pelaku rawat yang tidak memiliki hubungan suami atau istri mempunyai kualitas hidup yang kurang baik.

Tingkat stres sedang menstimulasi seseorang untuk beraktivitas dan menyelesaikan sesuatu (Zerwekh, 2006). Koping responden pada penelitian ini menunjukkan bahwa responden dengan koping adaptif lebih banyak dibandingkan dengan koping maladaptif. Hasil ini menunjukkan bahwa pelaku rawat informal telah mampu memilih koping yang tepat sebagai respon terhadap tingkat stresnya. Kondisi ini dapat terjadi mengingat religiutas masyarakat di Indonesia cukup baik. Indonesia adalah negara yang menjadikan ke-Tuhanan sebagai dasar Negara. Indrayani (2010) menyatakan bahwa individu pada masa dewasa awal mempunyai religiutas yang tinggi. Religiusitas memegang peranan yang besar dalam menghadapi masalah. Penelitian di sebelumnya di Pakistan menyebutkan bahwa pelaku rawat lebih menggunakan koping yang berhubungan dengan spiritualitas dan emosi (maladaptif) (Ijaz \& Ajmal, 2011). Koping 
tersebut disebabkan oleh sikap klien yang dirawat yang tidak kooperatif dan kurangnya pengetahuan tentang diabetes, serta masalah tentang kepercayaan klien terhadap pelaku rawat dan pengaturan dietnya.

Hal lain yang berhubungan dengan koping adalah masalah finansial. Masalah finansial ini berpengaruh terhadap perilaku distres pelaku rawat informal (Magnani \& Rammohan, 2006). Indonesia merupakan salah satu negara yang memberikan penghasilan rendah pada pekerja informal, termasuk pelaku rawat.

Hasil penelitian ini menunjukkan bahwa tidak ada hubungan antara karakteristik individu dengan tingkat stresnya. Hasil ini berbeda dengan penelitian sebelumnya. Evans (2011) menyebutkan bahwa karakteristik individu dapat memengaruhi respons terhadap stresor. Perbedaan ini dapat terjadi karena besar sampel penelitian ini kecil.

Hubungan dari karakteristik usia dengan tingkat stres pelaku rawat tidak signifikan pada hasil penelitian ini $(p>0,05)$. Hal ini berbeda dengan hasil penelitian pada pelaku rawat dengan klien skizophrenia yang mengidentifikasi bahwa faktor usia berhubungan positif dengan tingkat kewalahan atau stres dari pelaku rawat (Rafiyah \& Sutharangsee, 2011). Pelaku rawat senior lebih memiliki rasa khawatir selama merawat kliennya dibandingkan dengan pelaku rawat yang lebih muda. Hasil penelitian oleh peneliti juga menunjukkan bahwa pelaku rawat pada tahap usia dewasa awal memiliki stres tinggi yaitu sebanyak $21 \%$. Stres tinggi pada pelaku rawat ini dapat diakibatkan oleh faktor tertentu antara lain masalah pendapatan, waktu kerja, dukungan sosial, dan kesehatan fisik, selain dari karakteristik personal (Collin \& Swartz, 2011; \& Bauer \& Sousa-Poza, 2015).

Penelitian menyatakan bahwa perbedaan jenis kelamin tidak terlalu berpengaruh terhadap kinerja namun ada juga yang menyatakan bahwa perempuan lebih memiliki perasaan ter- tekan yang lebih tinggi, sehingga pelaku rawat perempuan lebih sering untuk tertekan atau merawat klien kurang dari waktu yang ditentukan (Bauer \& Sousa-Poza, 2015). Hal ini karena perempuan lebih fokus terhadap emosi yang dirasakan. Jenis kelamin dengan tingkat stress ini tidak berhubungan signifikan. Hal ini sesuai dengan penelitian yang menyatakan bahwa tidak ada hubungan antara jenis kelamin dengan tingkat kualitas hidup pelaku rawat (Awadalla, Ohaeri, Al-Awadi, \& Tawfiq, 2006). Tingkat kualitas hidup ini menunjukkan apakah stres pada pelaku rawat berdampak pada kualitas hidupnya atau tidak. Pelaku rawat dengan stress tinggi cenderung memiliki kualitas hidup yang kurang.

Tingkat pendidikan pada penelitian ini menunjukkan bahwa pelaku rawat informal yang berpendidikan tinggi memiliki tingkat stres tinggi. Sedangkan pelaku rawat dengan berpendidikan rendah mengalami tingkat stres sedang. Tidak ada hubungan antara tingkat pendidikan dengan tingkat stres pelaku rawat informal. Hal ini berbeda dengan hasil penelitian yang menyebutkan bahwa pelaku rawat dengan tingkat pendidikan rendah memiliki tingkat stres yang lebih tinggi dibandingkan dengan yang berpendidikan tinggi (Evans, 2011; \& Okoye \& Asa, 2011).

Faktor yang berpengaruh adalah pendapatan dan respons pelaku rawat terhadap stresor itu sendiri (NAC \& AARP, 2004; Okoye \& Asa, 2011; \& Rafiyah \& Sutharangsee, 2011). Meskipun begitu pelaku rawat dengan tingkat pendidikan rendah juga memiliki risiko untuk mengalami stres tinggi karena stres sedang merupakan tahap stres kedua sebelum terjadinya stres tinggi.

Pelaku rawat yang masih memiliki hubungan keluarga cenderung merasa bertanggung jawab atau memiliki peran terhadap perawatan klien. Penelitian sebelumnya menemukan bahwa pelaku rawat yang masih memiliki hubungan keluarga dengan klien biasanya memiliki peran lebih dari satu sehingga hal ini dapat mem- 
pengaruhi ketegangan emosional pelaku rawat yang berisiko tinggi (Schulz \& Sherwood, 2008). Hal ini berbeda dengan hasil penelitian yang telah dilakukan oleh peneliti dimana sebanyak $97 \%$ pelaku rawat yang sudah menikah mengalami stres sedang.

Lama perawatan yang diberikan pelaku rawat memengaruhi kondisi mental dan psikis pelaku rawat informal. Pelaku rawat yang baru melakukan perawatan pada klien memiliki perbedaan dengan pelaku rawat yang sudah lama melakukan perawatan. Schulz dan Sherwood (2008) menjelaskan bahwa pelaku rawat dengan intensitas perawatan sering dan waktu lama memiliki pengalaman distres secara psikologis yang meningkat. Hasil penelitian tersebut berbeda dengan hasil penelitian ini dimana pelaku rawat memiliki stres tinggi berada pada waktu perawatan kurang dari atau sekitar tiga bulan (belum pada kondisi perawatan lukakronis). Stres tinggi yang dialami pelaku rawat informal tersebut dapat berhubungan dengan intensitas yang dilakukan selama melakukan perawatan setiap harinya.

\section{Kesimpulan}

Hasil penelitian yang telah dilakukan kepada 40 pelaku rawat informal di Balai asuhan keperawatan wilayah Jabodetabek menggambarkan karakteristik pelaku rawat, yaitu setengah dari pelaku rawat berada pada tahap usia dewasa awal (20-40 tahun). Mayoritas pelaku rawat adalah perempuan dan sudah menikah. Sebagian besar pelaku rawat telah merawat sekitar 3 bulan. Pelaku rawat informal ini memiliki perbedaan tingkat stres. Sebanyak $95 \%$ responden mengalami tingkat stres sedang dan sisanya mengalami tingkat stres tinggi. Lebih dari setengah pelaku rawat informal menggunakan koping adaptif selama melakukan perawatan kepada klien dengan diabetes dan sebagian pelaku rawat informal dengan tingkat stres sedang menggunakan koping adaptif dalam perawatan paliatif. Tidak ada hubungan antara karakteristik pelaku rawat informal dengan tingkat stres.
Hasil penelitian ini merekomendasikan agar penyedia jasa pelayanan keperawatan paliatif lebih memperhatikan aspek psikologis para pelaku rawatnya. Selanjutnya perlu mengembangkan upaya untuk mencegah stres pada pelaku rawatnya dan mempertahankan pola koping adaptif yang sudah dilakukan. Upaya ini perlu dilakukan untuk meminimalkan stres klien dan keluarganya akibat perilaku pelaku rawatnya (TN, AM, INR).

\section{Referensi}

Aikens J.E., Zivin K., Trivedi R., \& Piette J.D. (2014). Diabetes self-management support using mhealth and enhanced informal caregiving. Journal of Diabetes and Its Complications, 28, 171-176. doi: 10.1016/ j.jdiacomp.2013.11.008

Awadalla, A. W., Ohaeri, J. U., Al-Awadi, S. A., \& Tawfiq, A. M. (2006). Diabetes mellitus patients' family caregivers' subjective quality of life. Journal of the National Medical Association, 98(5), 727-736. Diperoleh dari http://www.ncbi.nlm.nih.gov/pmc/articles/PM C2569270/

Bauer, J. M. \& Sousa-Poza A. (2015). Impact of Informal Caregiving on Caregiver Employment, Health, and Family. Population Aging, 1-33. Diperoleh dari http://ftp.iza. org/dp8851.pdf

Berman A., Snyder SJ, Kozier B, \& Erb G. (2008). Fundamental of nursing; Concepts, process, and practice. New Jersey: Pearson Education Inc.

Cohen S., Kamarck T., \& Mermelstein R. (1983). A global Measure of Perceived Stress. Journal of Health and Social Behavior, 2(4), 394-395.

Collin, L.G. \& Swartz, K. (2011). Caregiver care. Americam Family Physician, 83(11), 1309 1317. Diperoleh dari http://www.aafp.org/afp /2011/0601/p1309.html

Effendy, C., Vernooij-Dassen, M., Setiyarini, S., Kristanti, M.S., Tejawinata, S., Vissers, K., \& Engels, Y. (2015). Family caregiver's 
involvement in caring for a hospitalized patient with cancer and their quality of life in a country with strong family bonds. PsychoOncology, 24(5), 585-91. doi: 10.1002/pon. 3701 .

Evans, J.J. (2011). Individual differences in stress physiology: Understanding person by situation influences. Doctoral Dissertation. Faculty of the Graduate School of The University of Texas at Austin. Diperoleh dari: https:// repositories.lib.utexas.edu/handle/2152/ETDUT-2011-05-3494

Ferrara. M., Langiano, E., Di Brango, T., De Vito, E., Di Cioccio, L., \& Bauco, C. (2008). Prevalence of stress, anxiety, and depression in with alzheimer caregivers. Health and Quality of Life Outcomes, 6(93), 1-5. doi: 10.1186/ 1477-7525-6-93.

Ijaz, S. \& Ajmal, M. A. (2011). Experiencing type II diabetes in Pakistan. Pakistan Journal of Social and Clinical Psychology, 9, 50-56. Diperoleh dari http://gcu.edu.pk/ FullTextJour /PJSCS/2011/8.pdf

Indrayani, Y. (2010). Hubungan religiusitas, kematangan emosi, dan kecemasan terhadap masa depan pada dewasa awal. (Skripsi, tidak dipublikasikan). Program Studi Psikologi, Jurusan Bimbingan Konseling dan Psikologi, Fakultas Ilmu Pendidikan, Universitas Negeri Malang.

KEMKES RI. (2012). Buletin Jendela Data dan Informasi Kesehatan: Penyakit tidak Menular. Jakarta: Arsip KEMKES RI. Diperoleh dari: http://www.depkes.go.id/download.php?file $=\mathrm{d}$ ownload/pusdatin/buletin/buletin-ptm.pdf

Lee, M. (2008). Caregiver stress and elder abuse among Korean family caregivers of older adult with disabilities. Journal of Family Violence, 23, 707-712. doi: 10.1007/s10896-008-9195-2

Magnani, E. \& Rammohan, A.(2006). The effect of elderly caregiving on female labour supply in Indonesia. Diperoleh dari: https://www. business.unsw.edu.au/researchsite/centreforapp liedeconomicresearchsite/Documents/E. $\% 20 \mathrm{M}$ agnani $\% 20$ and $\% 20$ A. $\% 20$ Rammohan $\% 20 \% 20$ The $\% 20$ Effect $\% 20$ of $\% 20$ Elderly\%20Caregivi
ng\%20on\%20Female\%20Labour\%20Supply\% 20in\%20Indonesia.pdf.

National Alliance for Caregiving \& American Association of Retired Persons (AARP). Caregiving in the US. Diperoleh dari: http://www.caregiving.org/data/04finalreport.p df

National Institute of Nursing Research. (2011). Palliative care: The relief you need when you're experiencing the symptoms of serious illnes. Diperoleh dari: http://www.ninr.nih.gov /sites/www.ninr.nih.gov/files/Palliative-CareRelief-When-Experiencing-SymptomsSerious-Illness-508.pdf.

Okoye, U.O. \& Asa, S.S. (2011). Caregiving and stress: Experience of people taking care of elderly relations in south -eastern Nigeria. Arts and Social Sciences Journal, AASJ-29, 1- 9. Diperoleh dari http://astonjournals.com/ass

Rafiyah, I., Suttharangsee, W., \& Sangchan, H. (2011) Social support and coping of Indonesian family caregivers caring for person with schizoprenia. Nurse Media Journal of Nursing, 1(2), 159-169. Diperoleh dari http://ejournal.undip.ac.id/index.php/medianer s/article/viewFile/979/965

Rafiyah, I., \& Suttharangsee, W. (2011). Review: Burden on family caregivers caring for patients with schizoprenia and its related factors. Nurse Media Journal of Nursing, 1(1), 29-41. Diperoleh dari http://www.ejournal.undip.ac.id

Riasmini, N.M., Kanso, S., Sahar, J. \& Prasetyo, S. (2013). The effectiveness of independent family group model to reduce caregiver burden and improve the caregiver ability on providing care for elder person in community. IOSR Journal of Nursing and Health Science, 1(5), 57-64. Diperoleh dari http://iosrjournals. org/iosr-jnhs/papers/vol1-issue5/K0155764. pdf?id $=6554$

Schulz, R. \& Sherwood, P.R. (2008). Physical and Mentah Health Effects of Family Caregiving. Am J Nurs, 108 (9 Suppl), 23-27. doi: 10.1097/01.NAJ.0000336406.45248.4c 
Sinclair, A.J., Armes., D.G., Randhawa, G. \& Bayer A.J. (2010). Caring for older adults with diabetes mellitus: Characteristics of carers and their prime roles and responssibilities. Diabetic Medicine, 27, 1055-1059. doi: 10.1111/j.14645491.2010.03066.x.

Spillman, B.C. \& Long, S.K. (2009). Does high caregiver stress predict nursing home entry? Inquiry (00469580), 46, 140-161. Diperoleh dari http://www.ncbi.nlm.nih.gov/pubmed/ 19694388

Tobin, D. L. (2001). User manual for the coping strategies inventory. Diakses dari: dvto2@ aol.com

Zerwekh, J.V. (2006). Nursing care at the end of life: Palliative care for patients and families. Philadelphia: F.A. Davis Company. 